\title{
Cleft palate in Pierre Robin sequence
}

\author{
Houda Oubejja ${ }^{1,2,3,4}$, Imane Menbahi ${ }^{2}$, Chadi Elhasnaoui ${ }^{1,2}$, Souha Qurouach ${ }^{1,2}$, Ismail Benomar ${ }^{1,2}$, Fouad Fouad \\ Ettayebi ${ }^{1,2}$. \\ 1-Department of pediatric surgical emergencies, children's hospital of Rabat, Morocco. \\ 2-Faculty of medecine and pharmacy, University Mohammed V, Rabat, Morocco. \\ 3-Laboratory of health and biology, faculty of science, university IbnTofail Kenitra, Morocco. \\ 4-Laboratory of epidemiology, clinical research and Biostatistics, faculty of medecine and pharmacy, University \\ Mohammed V, Rabat, Morocco.
}

\begin{abstract}
:
Pierre Robin's sequence PRS is a congenital malformative sequence with a retrognathism, a glossoptosis and an upper respiratory obstruction with an associated cleft palate. This malformative association can be disabling for both the child and his parents, because of its aesthetic, functional, psychological and social impacts. Patients and methods: We have investigated 14 patients with PRS presenting cleft palates, collected over a period of 5 years, from March 2014 to November 2019 in the pediatric surgical emergencies department (PSE) in Rabat Children's Hospital (HER). Results: Nine of the 14 patients had a complete cleft palate. The average age of intervention was 23 months ranging from 13 months to 4 years. The study showed a slight female predominance $(\mathrm{n}=8,57 \%)$. Regarding the treatment, 3 patients were treated with the Bardach's technique, 3 had the Von Langenbeck's technique, 3 had the Push-back technique and one patient who suffered from a post-operative persisting velar division was treated by veloplasty $3^{\text {rd }}$ generation. The hospital stay was around 24 hours and the post-operative follow-up was uncomplicated for all our patients.

Conclusion: Although we had a relatively high success with our approach, the complexity and lack of consensus regarding the management of Pierre Robin's sequence still requires the involvement of a multidisciplinary team. The main aim is to give the best aesthetical and functional results in order to reduce the suffering of the PRS children and families.
\end{abstract}

Keywords: cleft palate, retrognathism, glossoptosis, dysmorphia, Pierre-Robin sequence, surgery.

\section{Introduction:}

Pierre Robin sequence (PRS) is a congenital malformative sequence of the face associating a retrognathism, a glossoptosis, and an obstruction of the upper airway (secondary to an abnormal position of the tongue). A cleft palate is often present, but is inconstent in the definition [1]. The word sequence is replacing here what was once considered to be a syndrome, because of the relationship between the different anomalies previously mentioned. The sequence is the result of a chain of events caused by one initial factor represented in the PRS by retrognatism. The retrognathism forces the tongue to fall back (glossoptosis) causing the obstruction of the upper airway. This glossoptosis, in addition to the obstruction of the upper airway is probably the cause behind the cleft palate. While half of the PRS cases are isolated, $50 \%$ are called syndromic, referring to an associated syndrome. The most common ones are Stickler, Treacher Collins and the velocardiofacial syndrome $(65 \%)$. To this day, the exact cause of PRS is still unknown. However, the hypoplastic mandible theory is mostly retained in the literature and has been demonstrated in animal models. The subsequent mandibular hypoplasia would then lead to a small mouth volume, an abnormal position of the tongue and an impaired closure of the palate. Furthermore, the SOX9 gene, has been linked to nonsyndromic PRS in families with more than one member affected. The diagnosis is mainly clinical and consists on a retrognathism and a glossoptosis with more or less a cleft palate. However, the severity of the sequence is determined by the severity of the feeding and respiratory difficulties, in addition to the functional and social impact. Therefore a multidisciplinary team should be involved in the management of children with PRS.

The aim of this study is to describe our experience in the management of PRS children, particularly the place of the palatoplasty.

\section{Patients and methods:}

We have investigated 14 patients with PRS presenting with cleft palates, collected over a period of 5 years, from March 2014 to November 2019 in the pediatric 
surgical emergencies department (PSE) in Rabat Children's Hospital (HER). The sociodemographic, clinical and radiological characteristics were analysed as well as the information about the treatment. Data was analyzed by excel 2017.

\section{Results:}

Our results showed a slight predominance of females compared to males, representing $57 \%$ of the patients with PRS. The majority of our patients were ranked equally $2^{\text {nd }}$ or $3^{\text {rd }}$ among their siblings, and these 2 groups accounted for a little more than $75 \%$ of our study sample. It was also noticed that in almost 4 families out of 5, the affected child was the last; this actually raises the question whether most parents were reluctant to having another child as a precaution.

Table 1: General characteristic of PRS's patient, pediatric surgical emergencies department, Children hospital of Rabat.

\begin{tabular}{|l|l|}
\hline Characteristics* & $\mathrm{n}(\%)$ \\
\hline Gender & $8(57 \%)$ \\
\hline Girl & $6(43 \%)$ \\
\hline Boys & \\
\hline Consanguinity & $11(78,6 \%)$ \\
\hline second degree & $1(7,1 \%)$ \\
\hline First degree & $2(14,3)$ \\
\hline Medication, drugs & \\
\hline None & $12(92,3 \%)$ \\
\hline Fenugreek & $1(7,7 \%)$ \\
\hline Type of cleft palate & \\
\hline Complete & $9(64,3 \%)$ \\
\hline Incomplete & $5(35,7 \%)$ \\
\hline Characteristics** & Mean $+\mathrm{SD}$ \\
\hline Birth weight & $2800+/-469$ \\
\hline Age at surgery & $23,3+/-12,8$ \\
\hline & \\
\hline
\end{tabular}

* expressed by number and pourcebnate, ${ }^{* *}$ expressed by mean and standard deviation

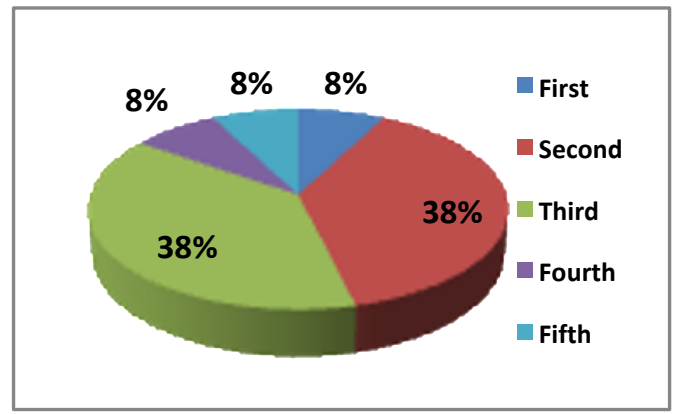

Figure 1: Pie chart showing the rank among their siblings

On the other hand, no relevant medical family's history was found and according to the mothers, no drugs or plants were taken during pregnancy, except in one case of fenugreek consumption. In addition, the average weight at birth was about $2800 \mathrm{~g}$, ranging from 2000 to $3800 \mathrm{~g}$. Almost $80 \%$ of the cases in our study were born of non-consanguineous parents, and out of the $20 \%$ remaining two were born of first-cousin parents and one of second-cousin parents.

Regarding the clinical manifestations, the most frequent sign was the facial dysmorphia, (Figure 2) in association with feeding difficulties, characterized by a regurgitation of milk through the nose. Rarely, a moderate respiratory difficulty was seen (Figure 3 ).

Furthermore, out of the 14 cases 9 had a complete cleft palate $(64 \%)$.
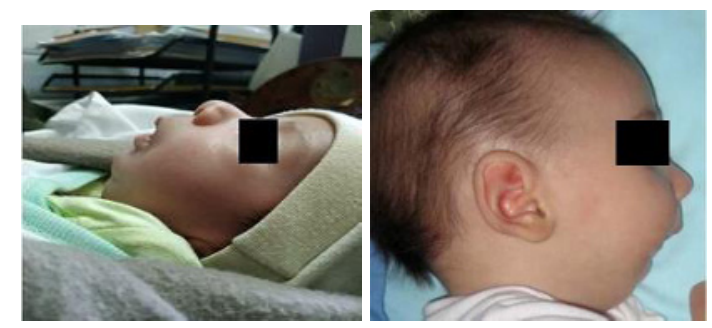

Figure 2: Lateral views of a retrognathism in infants with PRS

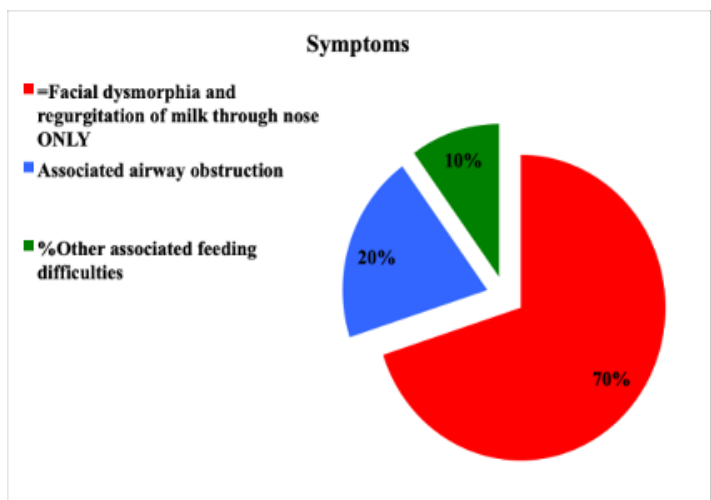

Figure 3: Pie graph showing the proportion of the revealing symptoms. 


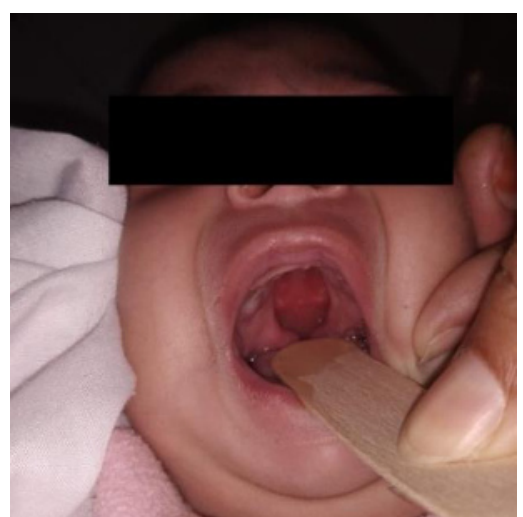

Figure 4 showing a complete cleft palate in an 8 months old boy.

In order to relieve the breathing difficulties during the neonatal period, the parents were advised to put them on a prone or a lateral position, and to regularly check the position of their tongue. A stable respiratory function and successful use of orthodontic devices, which were made at the faculty of dental medicine, allowing a closer to normal feeding, in order to reach a sufficient weight to be eligible for surgery. The average age of intervention was about 23 months, with an interval going from 13 months to 4 years. The patient who was in general good health, and whose biological and malformative tests were compatible with the surgery, was retained as a candidate for a reconstructive surgery.

Out of the 14 patients, 3 benefited from Bardach's technique (Figure 5), and 3 had Von Langenbeck's. In three cases, the Push-back technique was done and one patient had a surgical revision by veloplasty $3^{\text {rd }}$ generation. The four remaining patients were not operated on because of their age under 1 year.

The Immediate follow-up was uncomplicated for all our patients. Analgesics were prescribed during the first 48 hours and as for antibiotics, a ten days course of amoxicillin and clavulanic acid, was prescribed. It was advised to start feeding liquids by a syringe for 3 weeks before moving to baby bottles and solids.

In order to evaluate the results and detect any complication, all our patients were seen regularly, at day 7 or day 10 , then 1 month, every 3 months for a year and finally once a year.

The majority of our patients were referred to a speech therapist, as well as a in a genetic counseling.

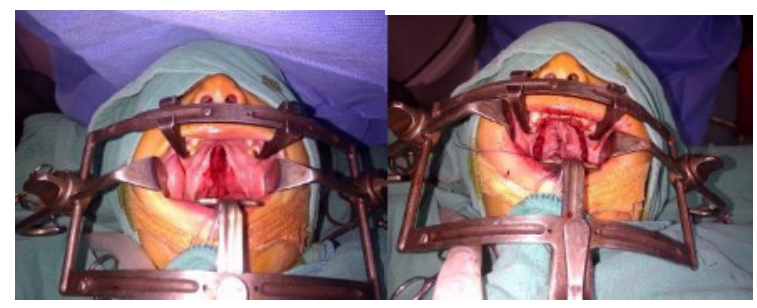

Figure 5: Frontal view of a cleft palate and immediate post operative results (Bardach's technique)

\section{DISCUSSION:}

The incidence of PRS varies from one country to another ranging from 1 out of every 8500 to 1 out of every 30000 live births [2]. From large series, it is reported that while half PRS cases are isolated the other $50 \%$ are syndromic, meaning associated with another syndrome, and the most frequent ones are Stickler, Treacher-Collins and the velocardiofacial syndrome, all of them representing $65 \%$ of the syndromic cases. The mortality rate in PRS infants varies considerably with extremes going from around $2 \%$ to $11 \%$; this rate increases even more to reach $26 \%$ when talking about syndromic cases only. One recent study reports an overall mortality rate at $16.6 \%$ with no mortality in isolated PRS, with highest mortality of the infants with cardiac or central nervous system anomalies at respectively $39 \%$ and $33 \%$.[3]

Finally, no predilection for gender was found in the literature, as both females and males were evenly affected.

To this day, the exact cause of PRS is still unknown. However, the hypoplastic mandible theory is the one mostly retained in the literature and the one that has been demonstrated in animal models.

The primary defect is thought to be in Meckel's cartilage (which is a structure involved in the formation and growth of the mandible), before the embryonic age of 9 weeks. The subsequent mandibular hypoplasia is thought to lead to a small mouth volume, abnormal position of the tongue, and the secondary impairment of palatal closure [1]. Furthermore, the SOX9 gene, a critical chondrogenic regulator, has been linked to nonsyndromic PRS in families with more than one member affected [4].

In the literature, the diagnosis is mainly clinical and consists on finding retrognathism, and a glossoptosis with more or less a cleft palate. In most cases, the severity of the sequence is determined by the severity of feeding and respiratory difficulties, in addition to the functional and social impact because of the related esthetic and speech deficits.

The evaluation of the airway obstruction is made in one hand by nasopharyngoscopy that allows the visualization of the site of obstruction at the base of the tongue as well as the diagnosis of other eventual anomalies that could change the course of action concerning the treatment choice [5]. On the other hand, the oximetry and the polysomnography can give a more objective measure of the severity of the airway obstruction and the degree of response to treatment [6]. However, the evaluation of feeding difficulties includes video fluoroscopic swallowing studies and endoscopic evaluations of swallowing $[7 ; 8]$

The PRS management is divided in two main blocks non-surgical and surgical options, according to the symptoms. In fact, the first option includes starting off with the positioning. The prone position is still the simplest and easiest treatment of the upper airway obstruction, allowing the mandible and tongue to fall forward to reduce the airway obstruction [9]. In some cases, a cephalic suspension is indicated in addition to 
the prone positioning. Compared to our experience, no cephalic suspension was required and a lateral position was suggested to the parents.

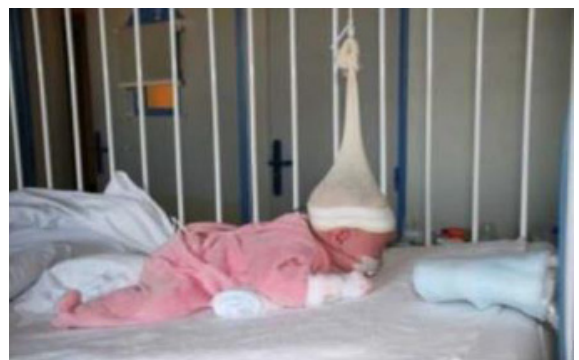

Figure 7: Lateral view of a cephalic suspension [11]

When positioning alone fails, tongue-base airway obstruction may be relieved by placement of a nasopharyngeal airway. Nevertheless, for long-term use at home, parents have to be taught the proper insertion technique, and since not all parents are receptive to this type of training and responsibility, it may end up prolonging their hospital stay [12]. Wagener and al [13] in 2003 kept the infants were in the hospital's long term care unit, as opposed to being discharged home following appropriate parent teaching.

The Continuous positive airway pressure or CPAP keeps the upper airway open at every step of the respiratory cycle (Figure 8). However, very few centers reported on the successful use of CPAP to treat airway obstruction in PRS. Also there was no information concerning a possible delayed maxillary growth secondary to prolonged CPAP use. Indeed, Kasey et al. [14] reported in 2000 a case of an acquired maxillary hypoplasia secondary to a prolonged use of CPAP .

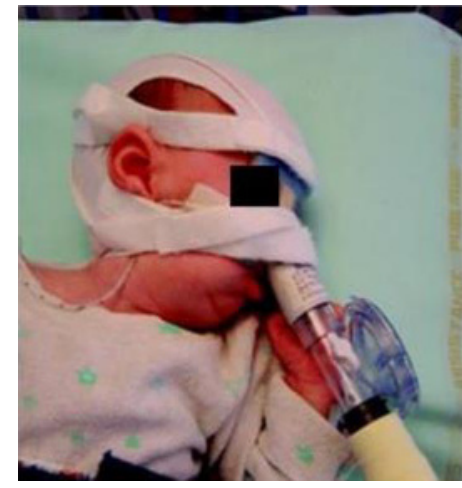

Figure 8: Lateral view of infant with a CPAP[15]

Similar to our experience, some centers used an orthodontic device only to help with feeding. There is, however, a few publications reporting on their success at decreasing upper airway obstruction. Butow and al. [16] described a significant success as high as $74 \%$ of the 188 treated infants, but still without providing any objective measures.

Regarding the surgical options, many techniques were found in the literature, like the tongue-lip adhesion (Figure 9) or labioglossopexy, first described in 1846 by Fairbairn and modified by Argamaso in 1992 [18]. This technique has been shown to relieve airway obstruction in carefully selected infants with PRS. However, it is used as a temporizing measure to manage airway obstruction before surgery.
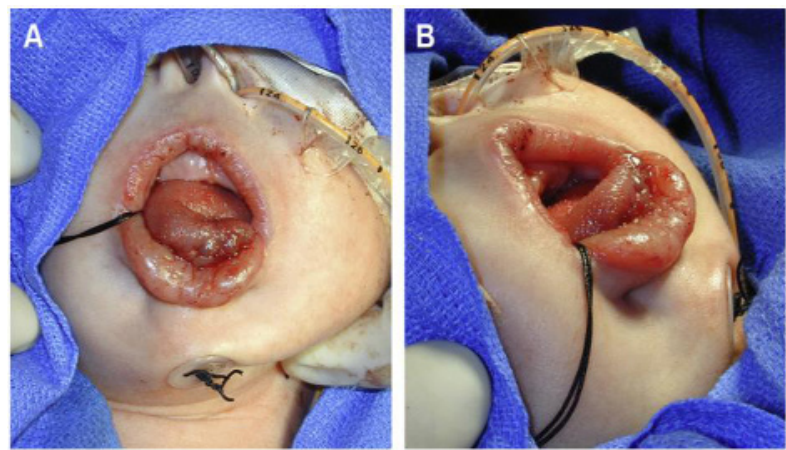

Figure 9: Frontal and lateral postoperative views of a Tongue Lip Adhesion [15].

Furthermore, some satisfying results following a mandibular distraction osteogenesis (MDO) were reported (Denny, 2005; Hammoudeh 2012). This technique consists of a slowly advancing of the mandible after an initial osteotomy [15,20, 21]( Figure 10)

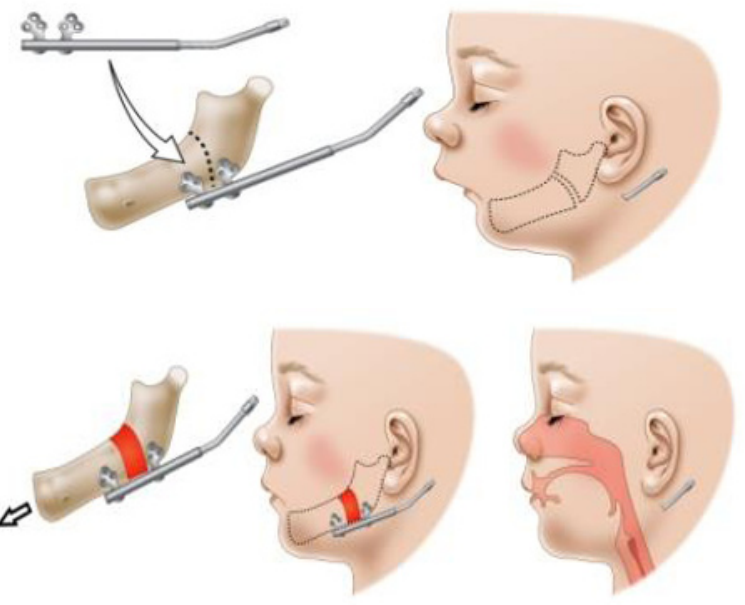

Figure 10: Illustration of a lateral view showing the steps to the mandibular distraction osteogenesis (MDO) [15,20, 21].

When all other measures have failed tracheotomy is considered to be the definitive treatment for severe airway obstruction. However, it can be associated with significant morbidity and mortality (0.5-7\%) [22-24].

The velopalatoplasty aims to treat cleft palates, there are numerous, all depending on the width and the length of the defect. The objective of this procedure is to close the palatal defect and create an adequately functioning velopharyngeal mechanism for normal speech production. The basic principle is the reconstruction of 3 layers, the nasal and buccal mucosae and the muscle in between.

In our practice, all our patients were managed by nonsurgical procedures before the palatoplasty. However, some conditions should be respected to do so, such as a stable respiratory function and successful use of orthodontic devices. Thus, the patients underwent different techniques according to the cleft 
type. In addition, the velopalatoplasty allows an easy follow-up especially in our context, a reduced duration of hospitalization (1-2 days) and an eventual normal growth of the mandible with time.

\section{Conclusion:}

Pierre Robin sequence is a triad associating a Retrognathism, a Glossoptosis and an Obstruction of the upper airway. The association with a cleft palate isn't included in the definition. A multidisciplinary approach should be established because of the variety of functions affected by this entity. The lack of guidelines in the management of PRS children only adds to the difficulties faced in order to treat them.

Our study, even though with relatively satisfying results, came to underline the necessity of having well structured and systematic guidelines in the management and the follow up of PRS children.

\section{References:}

[1] A. Côté, A. Fanous, A. Almajed, et Y. Lacroix, «Pierre Robin sequence: Review of diagnostic and treatment challenges $"$, Int. J. Pediatr. Otorhinolaryngol., vol. 79, $\mathrm{n}^{\circ} 4$, p. 451-464, avr. 2015, doi: 10.1016/j.ijporl.2015.01.035.

[2] A. Giudice et al., « Pierre Robin sequence: A comprehensive narrative review of the literature over time », J. Stomatol. Oral Maxillofac. Surg., vol. 119, $\mathrm{n}^{\circ}$ 5, p. 419-428, nov. 2018, doi: 10.1016/j.jormas.2018.05.002.

[3] M. A. Costa, M. M. Tu, K. P. Murage, S. S. Tholpady, W. A. Engle, et R. L. Flores, «Robin Sequence: Mortality, Causes of Death, and Clinical Outcomes », Plast. Reconstr. Surg., vol. 134, no 4, p. 738- 745, oct. 2014, doi: 10.1097/PRS.0000000000000510.

[4] S. Benko et al., « Highly conserved noncoding elements on either side of SOX9 associated with Pierre Robin sequence ", Nat. Genet., vol. 41, no 3, p. 359- 364, mars 2009, doi: 10.1038/ng.329.

[5] B. T. Andrews, K. L. Fan, J. Roostaeian, C. Federico, et J. P. Bradley, "Incidence of Concomitant Airway Anomalies When Using the University of California, Los Angeles, Protocol for Neonatal Mandibular Distraction »:, Plast. Reconstr. Surg., vol. 131, $\mathrm{n}^{\mathrm{o}}$ 5, p. 1116- 1123, mai 2013, doi: 10.1097/PRS.0b013e3182865da0.
[6] J. Schubert, H. Jahn, et M. Berginski, «Experimental Aspects of the Pathogenesis of Robin Sequence», Cleft Palate. Craniofac. J., vol. 42, $\mathrm{n}^{\circ}$ 4, p. 372-376, juill. 2005, doi: 10.1597/03-166.1.

[7] C. Miller et J. Willging, "The Implications of Upper-Airway Obstruction on Successful Infant Feeding », Semin. Speech Lang., vol. 28, $\mathrm{n}^{\mathrm{o}} 3$, p. 190-203, août 2007, doi: 10.1055/s-2007-984725.

[8] C. D. Pinheiro Neto, N. Alonso, L. U. Sennes, D. C. Goldenberg, et P. de P. Santoro, «Avaliação polissonográfica e de videoendoscopia da deglutição de pacientes portadores da sequência de Pierre-Robin », Braz. J. Otorhinolaryngol., vol. $75, \mathrm{n}^{\circ} 6, \mathrm{p}$. 852- 856, déc. 2009 , doi: 10.1590/S180886942009000600014.

[9] I. C. W. Anderson, A. R. Sedaghat, B. M. McGinley, R. J. Redett, E. F. Boss, et S. L. Ishman, "Prevalence and Severity of Obstructive Sleep Apnea and Snoring in Infants with Pierre Robin Sequence », Cleft Palate. Craniofac. J., vol. 48, $\mathrm{n}^{\circ}$ 5, p. 614- 618, sept. 2011, doi: 10.1597/10-100.

[10] T. Dwyer et A.-L. Ponsonby, «Sudden Infant Death Syndrome and Prone Sleeping Position », Ann. Epidemiol., vol. 19, no 4, p. 245- 249, avr. 2009, doi: 10.1016/j.annepidem.2009.01.024.

[11] «Antonin Cornu. Séquence de Pierre Robin : prise en charge néonatale et dévenir. Sciences du Vivant [q-bio]. 2016. »

[12] C. C. S. D. Mondini, I. L. Marques, C. M. B. Fontes, et S. Thomé, « Nasopharyngeal Intubation in Robin Sequence: Technique and Management », Cleft Palate. Craniofac. $J$, vol. 46, no 3, p. 258- 261, mai 2009, doi: 10.1597/08-042.1.

[13] S. Wagener, S. S. Rayatt, A. J. Tatman, P. Gornall, et R. Slator, «Management of Infants with Pierre Robin Sequence », Cleft Palate. Craniofac. J., vol. $40, \mathrm{n}^{\circ} 2$, p. 180- 185, mars 2003, doi: 10.1597/15451569_2003_040_0180_moiwpr_2.0.co_2.

[14] K. K. Li, R. W. Riley, et C. Guilleminault, «An Unreported Risk in the Use of Home Nasal Continuous Positive Airway Pressure and Home Nasal Ventilation in Children ", Chest, vol. 117, $\mathrm{n}^{\circ}$ 3, p. 916- 918, mars 2000, doi: 10.1378/chest.117.3.916.

[15] S. T. Hsieh et A. S. Woo, «Pierre Robin Sequence », Clin. Plast. Surg., vol. 46, $\mathrm{n}^{\circ} 2$, p. 249-259, avr. 2019, doi: 10.1016/j.cps.2018.11.010. 
[16] K.-W. Bütow, C. F. Hoogendijk, et R. A. Zwahlen, «Pierre Robin sequence: appearances and 25 years of experience with an innovative treatment protocol», $J$. Pediatr. Surg., vol. 44, no 11, p. 2112- 2118, nov. 2009, doi: 10.1016/j.jpedsurg.2009.04.018.

[17] T. W. Templeton, E. J. Goenaga-Díaz, C. M. Runyan, E. P. Kiell, A. J. Lee, et L. B. Templeton, «A generalized multistage approach to oral and nasal intubation in infants with Pierre Robin sequence: A retrospective review », Pediatr. Anesth., vol. 28, no 11 , p. 1029-1034, nov. 2018, doi: 10.1111/pan.13499.

[18] R. V. Argamaso, "Glossopexy for Upper Airway Obstruction in Robin Sequence », Cleft Palate. Craniofac. J., vol. 29, no 3, p. 232- 238, mai 1992, doi: 10.1597/1545$1569 \quad 19920290232$ gfuaoi 2.3.co 2.

[19] A. R. Sedaghat, I. C. W. Anderson, B. M. Mcginley, M. I. Rossberg, R. J. Redett, et S. L. Ishman, «Characterization of Obstructive Sleep Apnea before and after Tongue-Lip Adhesion in Children with Micrognathia », Cleft Palate. Craniofac. J., vol. 49, ${ }^{\circ} 1$, p. 21- 26, janv. 2012, doi: 10.1597/10-240.

[20] A. Denny et C. Amm, « New technique for airway correction in neonates with severe Pierre Robin sequence », J. Pediatr., vol. 147, $\mathrm{n}^{\circ}$ 1, p. 97-101, juill. 2005, doi: 10.1016/j.jpeds.2005.02.018.

[21] J. Hammoudeh et al., « Neonatal and Infant Mandibular Distraction as an Alternative to Tracheostomy in Severe Obstructive Sleep Apnea », Cleft Palate. Craniofac. J., vol. 49, $\mathrm{n}^{\mathrm{o}}$ 1, p. 32- 38, janv. 2012, doi: 10.1597/10069.

[22] W. Hoffman, «Outcome of Tongue-Lip Plication in Patients with Severe Pierre Robin Sequence »:, J. Craniofac. Surg., vol. 14, $\mathrm{n}^{\mathrm{o}}$ 5, p. 602-608, sept. 2003, doi: 10.1097/00001665-200309000-00002.

[23] L. Caouette-Laberge, C. Plamondon, et Y. Larocque, "Subperiosteal release of the floor of the mouth in Pierre Robin sequence: experience with 12 cases ", Cleft PalateCraniofacial J. Off. Publ. Am. Cleft PalateCraniofacial Assoc., vol. 33, $\mathrm{n}^{\circ}$ 6, $\mathrm{p}$. 468- 472, nov. 1996, doi: 10.1597/1545156919960330468 srotfo 2.3.co 2.

[24] L. de Trey, E. Niedermann, D. Ghelfi, A. Gerber, et C. Gysin, «Pediatric tracheotomy: A 30-year experience », $J$. Pediatr. Surg., vol. 48, n 7, p. 1470- 1475, juill. 2013 , doi: 10.1016/j.jpedsurg.2012.09.066.

[25] G. M. Dorrance et J. W. Bransfield, "The push-back operation for repair of cleft palate ", Plast. Reconstr. Surg. 1946, vol. 1, p. 145-169, sept. 1946.

[26] A. Habel, D. Sell, et M. Mars, "Management of cleft lip and palate.", Arch. Dis. Child., vol. 74, no 4, p. 360- 366, avr. 1996, doi: 10.1136/adc.74.4.360.

[27] J. Bardach, «Two-Flap palatoplasty: Bardach's technique », Oper. Tech. Plast. Reconstr. Surg., vol. 2, $\mathrm{n}^{\circ}$ 4, p. 211-214, nov. 1995, doi: 10.1016/S10710949(06)80034-X. 